\title{
EL ARTE DE ESTUDIAR COMO PRELUDIO DEL SABER VIVIR. \\ Una interpretación de las prácticas escolares como ejercicios espirituales
}

\section{The Art of Studying as a Prelude to Knowing How to Live. An Interpretation of School Practices as Spiritual Exercises \\ $A$ arte de estudar como prelúdio do saber viver. Uma interpretaçáo das práticas escolares com exercícios espirituais}

\author{
Edward A. Posada GómeZ
}

1 Doctor en filosofía de la Universidad Pontificia Bolivariana (Medellín, 2012). Magister en Filosofía de Pontificia Universitá San Tomasso D’Aquino ANGELICUM (Roma, 2009). Magister en Teología con énfasis en Sagrada Escritura de la Universidad Pontificia Bolivariana (Medellín, 2007). Actualmente coordinador del programa de Estudios Literarios de la Universidad Pontificia Bolivariana.

Correo electrónico: edward,posada@upb.edu.co

Artículo recibido el 30 octubre de 2016 y aprobado para su publicación el 10 diciembre de 2016. 


\title{
Resumen
}

La afirmación de la filosofía como "modo de vida" y, análogamente la de la teología, permite una re-significación de toda la vida escolar. Desde ella, prácticas escolares habituales como escuchar, preguntar, discutir, leer y escribir se convierten en factores fundamentales que propenden por la transformación del individuo. En este artículo, partiendo de la propuesta del filósofo francés Pierre Hadot, se buscará evidenciar dicha realidad a través de su concepción de los ejercicios espirituales. Como conclusión se perfilará una reflexión que pone de manifiesto que estudiar va más allá de ser una práctica dadora de conceptos y se convierte en un momento que preludia el saber más esencial en la experiencia humana: saber vivir.

\section{Palabras clave}

Prácticas escolares, Pierre Hadot, Ejercicios espirituales, Saber vivir.

\begin{abstract}
The idea of Philosophy -and also of Theology-as a "way of life" makes possible a reconsideration of scholar life. From this particular perspective, common school practices such as listening, questioning, discussing, reading and writing become relevant factors that contributes to the transformation of individuals. Based on the thought of the French philosopher Pierre Hadot, the article aims to show this reality through his idea of spiritual exercises. The conclusion is that studying should go beyond being a practice in which concepts are transmitted and should become a prelude to the most fundamental piece of knowledge of human experience: knowing how to live.
\end{abstract}

\section{Key words}

School Practices, Pierre Hadot, Spiritual Exercises, Knowing How to Live.

\section{Resumo}

A afirmação da filosofia como "modo de vida" e, analogamente a da teologia, permite uma ressignificação da vida escolar em sua totalidade. A partir dela, 
práticas escolares habituais como escutar, perguntar, discutir, ler e escrever tornam-se fatores fundamentais que propendem pela transformaçáo do indivíduo. Neste artigo, partindo da proposta do filósofo francês Pierre Hadot, tentará evidenciar-se tal realidade por meio de sua concepção dos exercícios espirituais. Como conclusão será esboçada uma reflexão que póe de manifesto que estudar vai mais além de ser uma prática dadora de conceitos, tornandose um momento que preludia o saber mais essencial na experiência humana: saber viver.

\section{Palavras-chave}

Práticas escolares, Pierre Hadot, Exercícios espirituais, Saber viver.

\section{LA PROVOCACIÓN}

Unas sugestivas palabras del Papa Benedicto XVI entronizan esta reflexión:

Los sarcófagos de los primeros tiempos del cristianismo muestran visiblemente esta concepción, en presencia de la muerte, ante la cual es inevitable preguntarse por el sentido de la vida. En los antiguos sarcófagos se interpreta la figura de Cristo mediante dos imágenes: la del filósofo y la del pastor. En general, por filosofía no se entendía entonces una difícil disciplina académica, como ocurre hoy. El filósofo era más bien el que sabía enseñar el arte esencial: el arte de ser hombre de manera recta, el arte de vivir y morir. Ciertamente, ya desde hacía tiempo los hombres se habían percatado de que gran parte de los que se presentaban como filósofos, como maestros de vida, no eran más que charlatanes que con sus palabras querían ganar dinero, mientras que no tenían nada que decir sobre la verdadera vida. Esto hacía que se buscase con más ahínco aún al auténtico filósofo, que supiera indicar verdaderamente el camino de la vida. Hacia finales del siglo III encontramos por vez primera en Roma, en el sarcófago de un niño y en el contexto de la resurrección de Lázaro, la figura de Cristo como el verdadero filósofo, que tiene el Evangelio en una mano y en la otra el bastón de caminante propio del filósofo. Con este bastón Él vence a la muerte; el Evangelio lleva la verdad que los filósofos deambulantes habían buscado en vano. En esta imagen, que después perdurará en el arte de los 
sarcófagos durante mucho tiempo, se muestra claramente lo que tanto las personas cultas como las sencillas encontraban en Cristo: Él nos dice quién es en realidad el hombre y qué debe hacer para ser verdaderamente hombre (Spe salvi, 6).

Para nosotros, que contemplamos estas figuras, su vida y su comportamiento son de hecho una " prueba » de que las realidades futuras, la promesa de Cristo, no es solamente una realidad esperada sino una verdadera presencia: Él es realmente el «filósofo » y el «pastor» que nos indica qué es y dónde está la vida (Spe salvi, 8).

Esta extensa cita del emérito Papa, en palabras de Ricoeur, "da qué pensar". Para los fines de esta reflexión, se resaltan tres aspectos:

- La figura del filósofo y el pastor bien pueden encarnar la metáfora de una quaestio disputata desde los orígenes del cristianismo, a saber, la dialéctica fe-razón, teología-filosofía, religión-ciencia que, en el fondo, es siempre el planteamiento de una cuestión epistemológica: filosofía y teología, ¿se oponen, se excluyen o se complementan?

- Otra de sus expresiones refiere una importante constatación histórica: "“'Por filosofía no se entendía entonces una difícil disciplina académica, como ocurre hoy. El filósofo era más bien el que sabía enseñar el arte esencial: el arte de ser hombre de manera recta, el arte de vivir y morir". Con estas palabras el Papa se inserta en una tradición antigua que está cobrando fuerza al interior de la reflexión filosófica hodierna: la afirmación de la filosofía como "modo de vida".

- Por último, la figura de Cristo con el bastón del filósofo en una mano y el evangelio en la otra, expresa cómo el cristianismo supo sintetizar en Cristo las aspiraciones de la filosofía antigua con la revelación: "La figura de Cristo como el verdadero filósofo, que tiene el Evangelio en una mano y en la otra el bastón de caminante propio del filósofo". De hecho al afirmar también que "Él es realmente el « filósofo » y el " pastor " que nos indica qué es y dónde está la vida" no sólo permite releer la comprensión de Jesús como filósofo sino que, con ello, se expresa una honda posibilidad de posicionar a la teología y a la filosofía en un campo de comprensión semejante.

Desde estos tres corolarios emerge la idea directriz de estas líneas: la filosofía y la teología, si bien se distinguen académicamente por la precisión 
de su objeto, sujeto y método, en el fondo están permeadas por un mismo espíritu humanista: ambas son un modo de vivir, un modo de ser, un modo de existir. Desarrollar esta afirmación es lo que se propone este escrito. Para ello se expondrá una breve comprensión de la filosofía como modo de vida y luego se propondrá una comprensión de las prácticas escolares en el estudio de la filosofía y la teología como ejercicios de conversión vital.

\section{LA CONCENTRACIÓN}

Afirmar que hacer, pensar o estudiar teología sea un modo de vida, parece una cuestión de perogrullo. De hecho se constata en la tradición de la Iglesia que sus grandes teólogos suelen coincidir con sus grandes santos. Teología y Santidad pertenecen a un mismo campo semántico pues una recta concepción de la teología reclama la oración y la conversión. Si bien es cierto que no pocos han denunciado a lo largo de la historia la presencia de teólogos no creyentes, especialistas de Dios, legalistas de un sistema religioso que incluso puede ser clarividente en los conceptos pero opresor en la vida, se ha de confiar en que estos sean casos excepcionales que confirmen la norma. Se asume, pues, que la práctica teológica reclama una vida teologal y esto implica asumir el desafío de la conversión personal.

No corre con la misma suerte la filosofía. La opinión vulgar suele asociar filosofía con discursos complicados, abstractos, inútiles, alejados de la realidad y superfluos. Una vieja expresión irónica, no exenta de ignorancia, gusta afirmar que la filosofía es aquello con lo cual o sin lo cual la vida sigue tal cual. ¡Pobre comprensión!

Esta concepción no es ya sostenible para una persona que se aplique juiciosamente al estudio de la filosofía. Un grupo de estudiosos actuales que incluye filósofos, historiadores, filólogos, sociólogos, han dedicado sus esfuerzos a la relectura de la historia de la filosofía redescubriendo en ella un auténtico modo de vida. Entre ellos se podría citar a la norteamericana Martha Nussbaum, al griego Alexander Nehamas, al español Gabriel Arnaiz y a los franceses Luc Ferry, André Compte Sponville o Pierre Hadot, entre otros. Su literatura no solo es un dedicado esfuerzo académico que busca desentrañar esta verdad en los textos de los filósofos de todos los tiempos, sino que se han empeñado en acercar la filosofía a todas las gentes. 
El resultado de sus trabajos alcanza una preciosa convicción antiquísima: la filosofía antes que ser solo un ejercicio teórico, es una opción ética. Los cursos en las antiguas escuelas griegas tenían tres bloques (un esquema tripartito mucho más evidente en la academia y el estoicismo): física, lógica (retórica) y ética. Las tres áreas estaban atravesadas por la ética. Saber pensar, saber hablar y reconocer el entorno con el fin de saber vivir. Había un discurso ético, pero también una ética vivida; un discurso físico y una física vivida; un discurso lógico junto a una lógica vivida. Es decir, al lado de la física está la ecología y al lado de la lógica la pasión por la verdad. El saber siempre con fines éticos.

Esta convicción fue lo que permitió que el título de filósofo no se le atribuyera en la antigüedad solo a los que creaban una doctrina novedosa en el ámbito del pensar, sino a todos aquellos que pertenecían a una escuela filosófica y, por ende, tenían una vida en común donde se abordaban una temáticas puntuales y se regían por unos principios de vida que, según la escuela, hicieran más soportable la existencia en la ciudad. Por ello, también eran filósofos hombres de la vida pública como Musonio Rufo, por ejemplo.

Esta constatación da nuevas luces al quehacer filosófico desde sus orígenes. Desde ella los discursos, las escuelas, el filósofo y el entramado del pensamiento, toman un nuevo cariz. Algunos de los aspectos que permiten repensar la filosofía como modo de vida se resumen a continuación.

\section{La filosofía como terapéutica de la vida}

Una antigua convicción confiesa que la filosofía es curativa, es terapéutica, cura los males de la vida, la filosofía ayuda a vivir. Una máxima epicúrea lo reza con vehemencia: "Vana es la palabra del filósofo que no cure los sufrimientos del alma. Pues del mismo modo que no es útil la medicina a menos que cure las enfermedades del cuerpo, tampoco lo es la filosofía si no sirve para suprimir las enfermedades del alma".

Esta preocupación por el cuidado del alma ya era explícita en Sócrates, con quien la filosofía toma una marcada dirección ética. En Sócrates el cuidado del alma no solo es lo esencial, sino que está por encima de los cuidados del cuerpo y de los bienes. Emblemático es en este sentido el discurso de Sócrates: 
¡Cómo Querido amigo!, tú que eres ateniense, ciudadano de una ciudad que es la más grande, la más renombrada, por su ciencia y su poderío, y no te ruboriza en poner cuidado de tu fortuna, a fin de incrementarla lo más posible, así como tú reputación y tus honores. Pero en lo que se refiere a tu razón, la verdad de tu alma, que habría de mejorar sin descanso, no te inquietas por ellas, y ni siquiera las tienes en consideración (Platón, 29d-30b).

La tarea fundamental del hombre, según Sócrates, consiste en ejercitarse plenamente en el cuidado de sí, la reconocida epimeleia, la cual inicia con el cuidado del alma que equivale a decir "inquietud de sí mismo, el hecho de ocuparse de sí mismo, preocuparse por sí mismo" (Foucault, 2005, p. 15. La ampliación y quizá la radicalización de este aspecto llega a la filosofía griega con la reflexión de las escuelas helenísticas en los tiempos de la crisis alejandrina. De ellas la recibirá la era cristiana cuando el estoicismo romano la proponga como cura sui. Desde Grecia hasta Roma, desde el s. V a.C. hasta el cristianismo, es claro que filosofía y medicina se reclaman. El poder de la filosofía es curar los males del alma o, por lo menos, contenerlos.

\section{Vivir la filosofía en comunidad}

Otro rasgo fundamental en la antigüedad que revela la dimensión vital de la filosofía radica en que el filósofo antiguo vivía su opción en el marco de una comunidad de filósofos, raramente en soledad. Un caso atípico se da en los cínicos pero, según Hadot (1995), en el pensamiento antiguo el filosofar estaba determinado por una elección de vida y esta vivida siempre en contexto comunitario (p. 18).De tal manera que una escuela en la antigüedad no respondía solo al deseo de formar una comunidad académica para refutar teóricamente otros sistemas, sino y, ante todo, como un espacio para vivir la propia elección de vida y fortalecerla con una experiencia solidaria mediante la enseñanza, bien sea oral en las lecciones enseñanza esotérica - o escrita en los manuales - enseñanza exotérica -. Este aspecto fue mucho más explícito desde la academia donde el diálogo como encuentro con el otro era uno de los ejercicios filosóficos fundamentales y, de hecho, se vio la necesidad de reservar un espacio físico para dichos encuentros, costumbre que fue seguida por escuelas posteriores como el liceo, el jardín y la stoa. 


\section{La experiencia de la conversión}

Unido a la experiencia comunitaria viene otro aspecto esencial: la conversión. Estas son las palabras de Hadot (2002):

Esta elección de vida no se da nunca en soledad: filosofía y filósofos se encuentran siempre al interno de un grupo, de una comunidad, en una palabra, de una "escuela filosófica". Y, para mayor claridad, una escuela filosófica corresponde en consecuencia, primero que todo, a una elección de un cierto modo de vivir, a una cierta elección de vida, a una opción existencial que exige del individuo un cambio total de vida, una conversión de todo su ser; es decir, un cierto deseo de ser y de vivir de cierto modo (234).

Cuando el hombre decide ser filósofo emprende un proceso de conversión: "El filósofo tendrá la tendencia a pensar que la única y auténtica transformación del hombre estriba en la conversión filosófica" (Hadot, 2002, p. 234). La conversión en cualquiera de sus dos acepciones, bien como retorno al origen o bien como mutación, será el mecanismo mediante el cual el hombre supera las falsas representaciones. En el caso de los estoicos, por ejemplo, la conversión les conduce a descubrir qué depende del hombre y qué no. En el caso de los epicúreos, los ejercicios espirituales les ayudan a superar el miedo a los dioses y a la muerte. En ambos casos la fuerza filosófica contribuye a superar los falsos conceptos al punto de otorgar al alma una cierta imperturbabilidad que le permite experimentar la felicidad. La conversión es terapéutica porque libera la vida de sus falsedades tanto físicas como lógicas y morales.

\section{Las prácticas filosóficas}

Esta experiencia de conversión no brota de la nada. En la comunidad filosófica la reflexión conduce a la detección de unas prácticas que favorecen la renovación del pensamiento y, a través de él, de la vida entera. Bien podrían llamarse prácticas filosóficas. Hadot, quien se dedicó al estudio de ellas con pasión, quiso ponerles un nombre bastante sugestivo para la tradición occidental. Les llamó ejercicios espirituales. Aclara él que, sin aludir a los ejercicios de Loyola, pero sin descartarlos del todo, le pareció bien este mote para denominar aquellas prácticas de los filósofos antiguos que les ayudaban en su proceso de conversión. Por ejercicio espiritual entiende el 
El arte de estudiar como preludio del saber vivir. Una interpretación

de las prácticas escolares como ejercicios espirituales

autor: "Ejercicio espiritual es una práctica voluntaria, personal, destinada a operar una trasformación del individuo, una transformación de sí" (p. 145). También, de él mismo, hay otra definición más descriptiva: "Ejercicio espiritual es una práctica de orden físico como el régimen alimentario o discursivo como el diálogo o la meditación o, aún más, intuitivo como la contemplación. Todas ellas destinadas a obrar una modificación o transformación del sujeto que las practicaba” (p. 22).

Los ejercicios, por tanto, son un camino a la renovación del ser. Por eso un filósofo no es sólo quien sabe determinado discurso, sino quien acompaña su vida con la práctica de unos determinados ejercicios que no sólo lo mantienen firme en la opción fundamental, sino que además le ayudan a renovarse todos los días.

Hasta aquí algunas de las líneas que delimitan la comprensión de la filosofía como modo de vida.

\section{La recepción de la filosofía antigua en el cristianismo primitivo}

Como se puede ver, estas mismas notas perviven en la experiencia de la Revelación cristiana. Si bien con una connotación nueva por la irrupción del Absoluto en la historia en la persona de Jesucristo, también es cierto que no se aleja absolutamente de las búsquedas que el hombre ha hecho de sí mismo y por sí mismo. Es por ello que el cruce entre el helenismo y el cristianismo fue un choque titánico, creador de cultura y civilización. Aún hoy la cultura está marcadamente helenizada y cristianizada. Basta contemplar la arquitectura, el arte, la música y hasta las concepciones morales platonizantes que subyacen en algunos sectores de la fe cristiana.

Como bien lo insinuaban las palabras del Papa Benedicto XVI en la cita inicial, el cristianismo pronto se percató de cómo lo esencial de la vida es encontrarle el sentido y por eso no esquivó el auxilio de todas las figuras de la época para referirlas análogamente a Cristo: el Pastor, el Salvador, el Mesías, el Paramédico, el Filósofo. Con la manera como se venía comprendiendo la filosofía en el periodo helenístico romano, como modo de vida, el cristianismo encaja perfectamente como una filosofía, pero los primeros cristianos han llevado dicha convicción al extremo y han presentado el cristianismo como la filosofía. Ya Clemente de Alejandría había avanzado algo en este aspecto, sobre todo con la coyuntural propuesta del 
logos como intermediario entre Dios y el mundo. De donde el logos era la palabra creadora y reveladora de Dios (Spanneut, 1957).

En el siglo II, los llamados padres apologistas griegos asumieron definitivamente el concepto logos para definir el cristianismo como la filosofía y con mayor razón pues si los filósofos antiguos son llamados así habiendo recibido sólo fragmentos del logos, cuánto más los cristianos que, al abrazar la fe, lo poseen en plenitud, es decir, el discurso verdadero y la razón perfecta encarnada en Jesucristo. Si filosofar significa vivir conforme a la razón - estoicos -, los cristianos son filósofos porque viven conforme a la razón divina. Esta acentuación del cristianismo como filosofía tomará formas más radicales con Clemente de Alejandría y Justino.

En la misma línea de la filosofía antigua, también la filosofía cristiana se presentará bajo la forma de discurso y modo de vida. Sin embargo la clave para poder presentar el cristianismo como la filosofía no radica solo en el método exegético que comparte con la filosofía pagana, sino radicalmente porque el cristianismo es un modo de vida como lo era la filosofía antigua. Un modo de vida que consiste en vivir según el logos, según la razón que es Cristo el Señor. El mismo Justino llega a afirmar que quienes antes de Cristo han guiado su vida por la razón son cristianos aunque sean considerados ateos como Sócrates o Heráclito (Apología I. 46. 3).

El cristianismo, pues, ha podido retomar la palabra filosofía para hablar de la perfección de la vida cristiana justo porque esta indicaba también un modo de vida. Al retomar la palabra, el cristianismo introduce del mismo modo prácticas y actitudes de la filosofía profana. Si ambas tienen numerosas analogías se debe especialmente a que el cristiano, como el filósofo, ha debido convertirse, elegir un modo de vida que lo conduzca a transformar su manera de mirar el mundo y la vida y, en cierto modo, también lo separa del mundo. El cristianismo es, indiscutiblemente, un modo de vida; de ahí que en medio de tantas visiones separatistas, en el fondo hay una significativa continuidad entre filosofía y teología, aunque obviamente existen peculiaridades que no se pueden soslayar. No obstante es propio de las visiones místicas y espirituales, tender más a la unidad que a la separación. Este esfuerzo investigativo pretende ser un servicio a esta tendencia y se hace explícito en el siguiente proyecto. 


\section{EL PROYECTO}

Ahora bien, desde los postulados propuestos, ¿cómo poner en marcha el proyecto del título de este artículo? Si la filosofía y la teología son modos de vida, ¿cómo puede ser su estudio un ejercicio espiritual y, por ende, preludio del saber vivir?

Hay que recordar que las actuales escuelas o claustros universitarios hunden sus raíces en los antiguos claustros filosóficos y cristianos. Piénsese en las scholé como la academia, el liceo o el jardín y en las escuelas cristianas como la monástica, la palatina y la catedralicia hasta llegar a la universitas. Todas ellas con el ideal de la paideia. Los actuales espacios no sólo reencarnan la antigua scholé y la universitas, sino que estudiar hoy puede ser, como en otros tiempos y según el espíritu de la época, un espacio para la conversión personal y así asumir un nuevo modo de vida. ¿Cómo lograrlo? La respuesta es antigua y ya está dada: con la práctica de ejercicios espirituales.

Pierre Hadot (1995) enumera, cita y estudia una buena cantidad de los ejercicios espirituales de los filósofos antiguos (pp. 291-330), pero este escrito no pretende ahora presentarlos detenidamente sino que, partiendo de él se distancia. Se rescatarán tres ejercicios espirituales inspirados en él y en las prácticas escolares, pero no son enumerados por el autor francés sino que es un ejercicio hermenéutico fruto de la fusión de horizontes entre el filósofo y el presente artículo. La labor educativa desde ayer hasta hoy se desenvuelve alrededor de unas actividades perennes. Ellas espiritualizadas, se convierten en verdaderos ejercicios espirituales. He aquí tres de ellos.

\section{Saber escuchar}

Desde los albores de la cultura, la educación se ha dado, tanto en la casa como en las escuelas, con la típica relación Maestro - discípulo. Esta relación está motivada por el deseo de saber del primero quien será "nutrido" (alere -alumno) con la experiencia y la sabiduría del maestro.

Si bien la educación sapiencial juega con el equilibrio entre la palabra y el silencio, es indudable cómo ha sido predominante la palabra habladafonética en la labor educativa. Generalmente y mucho más vigente en nuestros días, el maestro habla y el alumno escucha y, aunque sea un modelo en revisión por renombrados pedagogos en aras de una formación más 
constructivista y comunitarista, es evidente que el vetero modelo permanece. Esta actitud, sin embargo, no tiene por qué ser condenada. Por el contrario, una relectura podría producir abundantes frutos para la vida del espíritu.

La filosofía greco - romana alcanzó una bella comprensión de las lecciones orales (Pérez Cortés, 2004). Por un lado la oralidad misma ha tenido una gran valoración sobre la escrita. En efecto, la palabra es mucho más fecunda por cuanto es más integral. Toda lección hablada es dramaturgia. El maestro entona, vocaliza, canta, poetiza, subraya, enfatiza, a la par que mediante su pasión, contagia. Este era el poder de Sócrates, el maestro que nunca escribió. Lo mismo que Buda y Jesús. Estos grandes maestros fueron amantes de la palabra oral por encima de la escrita, quizá porque ellos sabían que sus palabras iban acompañadas de su vida. Sus palabras "señalaban" pero sus gestos "mostraban" y en esta medida eran capaces de decir lo indecible. Esto es lo que afirma la experiencia de lo "místico" con la cual termina L. Wittegenstein su Tractatus logicus philosophicus. Así pues, la palabra oral sigue siendo una de las riquezas del actual modelo pedagógico presencial.

Pero más allá de esto hay otra dimensión. La posibilidad de comprender la lección maestro - discípulo como una auténtica dirección espiritual. Este aspecto es subrayado por Hadot (1995, p. 322), pues enumera este ejercicio como uno de los modos en los que el individuo entra en contacto con su congénere. En su reflexión trae a colación este testimonio de Simplicio:

¿Cuál es el puesto del filósofo en la ciudad? Él será un escultor de hombres y un artesano que fabrica ciudadanos leales y dignos. No existe otra labor que cuidar de la purificación de sí mismo y de los demás, para vivir la vida conforme a la naturaleza que conviene al hombre. Él será un padre común y un pedagogo de todos los ciudadanos, su reformador, su consejero, su protector, ofrecerá a todos su colaboración en la realización de cualquier obra buena, disfrutando la felicidad de los felices y consolando a quienes están tristes (p.322) ${ }^{2}$

2 Los testimonios de autores antiguos, excepto que se señale lo contrario, corresponden a la traducción francesa desde el original griego o latino realizada por Pierre Hadot. La 
El arte de estudiar como preludio del saber vivir. Una interpretación de las prácticas escolares como ejercicios espirituales

Este testimonio muestra cómo la dirección espiritual apunta a una educación primera y fundamentalmente individual y personalizada. A través de ella, el discípulo toma conciencia de sí, tanto de sus defectos como de sus progresos y le ayuda a renovar diariamente su elección de vida. En este aspecto Sócrates sigue siendo modelo por excelencia, él es el paradigma del director espiritual que con sus discursos y, sobre todo con su modo de ser, provoca un movimiento en el interior de aquel que lo escucha, obligándolo a poner en discusión su propia vida. Pero para tal fin, atestigua Platón, es necesaria una predisposición sincera al diálogo. Pues sólo en este contexto de apertura interior, podrá el discípulo aceptar sus errores y transformarlos (Platón, Carta VII, 330c-331a).

El modo de hacerlo, aún en medio de las lecciones grupales, lo explica Marco Aurelio:

[...] sin humillarlo, sin hacerle sentir que es pesado, sino con sinceridad y bondad... con dulzura, sin ironía, sin humillar sino con afecto, con un corazón limpio de amargura, sin impartir enseńanza como en una escuela, ni tampoco para hacerse admirar como si fuera un coloquio, sino como una relación personal, individual, aunque otros estén presentes (Hadot, 1995, p. 332).

Esta misma experiencia tiene carta de ciudadanía en la experiencia teológica. Un caso paradigmático es la relación espiritual entre San Agustín y San Ambrosio. Muchos textos relatan esta experiencia pero las confesiones son un testimonio de primera mano. Agustín se sentía embelesado, embebido, eclipsado por las predicaciones de Ambrosio. Este era un hombre lejano; difícilmente se podía acceder a él. Pero Agustín sentía que las palabras proferidas por éste desde el púlpito no eran para todos los feligreses, sino para él. Dado que no podía hablar con su maestro en soledad, Agustín asistía a las predicaciones de Ambrosio consciente de que su corazón ya no sería igual. De lejos, entre muchas personas, Ambrosio era un maestro pero, más aún, un director espiritual para Agustín (Sampson, 1997). En el s. XIII, con

referencia precisa se halla en los textos del mismo autor. La traducción al español es personal. 
la "escolástica", quedará mucho más claro que desde hacía muchos siglos el púlpito ya era un tablero y la catedral un aula.

Esto evidencia que cuando un discípulo cree en el poder de la palabra y cuando logra empatizar con su Maestro, el hombre corriente no debe esperar a subir a la montańa como lo narran los cuentos orientales, para alcanzar sabiduría sino que en el diario trasegar de sus lecciones, la palabra del maestro puede fecundar el espíritu para hacerlo germinar con nuevo vigor. Cada clase es una dirección espiritual y quizá con un poder mayor sobre aquella que se ejerce de manera personalizada ya que el conocimiento empodera a la persona cultivándole un pozo interior al cual puede acudir cada vez que sus estados vitales reclamen discernimiento.

Esto, obviamente, precisa de una férrea convicción por parte del maestro y el discípulo, pues tampoco cualquier actitud conduce a la conversión. En su texto Lecciones de los maestros, George Steiner (2004) anuncia y denuncia las posibilidades que se pueden dar en esta relación y señala de paso la ideal para esta propuesta de una dirección espiritual:

Simplificando, podemos distinguir tres escenarios principales o estructuras de relación. Hay maestros que han destruido a sus alumnos psicológicamente y, en algunos casos, físicamente. Han quebrantado su espíritu, han consumido sus esperanzas, se han aprovechado de su dependencia e individualidad. El ámbito del alma tiene sus vampiros. Como contrapunto, ha habido discípulos, pupilos, aprendices que han tergiversado, traicionado y destruido a sus maestros. Una tercera categoría es la del intercambio: el eros de la mutua confianza e incluso amor (el discípulo amado de la última cena). En este proceso de interrelación, de ósmosis el maestro aprende de su discípulo cuando le enseńa. La intensidad del diálogo genera amistad en el sentido más elevado de la palabra. Puede incluir tanto la clarividencia como la sinrazón del amor. Hay discípulos que se han sentido incapaces de sobrevivir a sus maestros" (p. 7)..

He aquí algunos de los argumentos por los cuales las lecciones orales y presenciales pueden ser ejercicios espirituales. 
El arte de estudiar como preludio del saber vivir. Una interpretación

de las prácticas escolares como ejercicios espirituales

\section{Saber dialogar}

Toda experiencia de clase es un ejercicio de diálogo, quizá el método más antiguo de la enseńanza como se acaba de afirmar. Sócrates siempre estaba dialogando; los padres judíos catequizaban a sus hijos la noche de Pascua mediante el ejercicio pregunta - respuesta. Platón tomó de Sócrates este método y lo perfeccionó. Fue tan crucial el método en la Academia que las obras tomaron este nombre: los diálogos. Jesús también dialogaba con los discípulos y, en discusiones coyunturales, Jesús prefiere preguntar antes que afirmar: ¿quién te ha juzgado? (Jn. 8, 10) ¿Qué quieres que haga por ti? (Mc. 10, 50). El diálogo pone en juego todo el universo espiritual de la persona y especialmente en la pregunta cuando mueve las emociones, los pensamientos, los argumentos.

En el aula de clase se emprende un doble diálogo. El primero es el diálogo con uno mismo. Esta convicción reclama el antiguo oráculo que conduce a la sabiduría: "conócete a ti mismo". El proceso de escucha y meditación en las lecciones debe abrir el corazón a la novedad del conocimiento. La novedad irrumpe en la vida interior desestabilizando. Es muy posible que en las lecciones los valores y las verdades regentes hasta el presente entren en crisis. ¡Deben entrar en crisis! $Y$ es por ello que, de repente, muchas clases se suspenden entre la realidad y la imaginación mientras el espíritu se encuentra en lucha consigo mismo. Es una sensación agónica: ¿Qué sé de mí? ¿Qué sé de los dioses? ¿Qué sé del mundo? ¿Qué sé de la vida, el dolor, la muerte, el amor? La lección nunca será fecunda si no se vive en clave de introspección. Estudiar es meditar. Por eso luego de la edad de oro de la patrística, donde el cristianismo gozó de libertad ciudadana, apoyo político y pudo explayarse en prédicas y construcciones, se instauró la época monacal, quizá como un signo de que la educación no se da solo por la palabra sino también por el silencio. El monje es aquel que medita las palaras del Maestro interior. Siempre en dialogo consigo mismo. Una figura muy similar a aquella de los interlocutores de Sócrates, que regresaban a sus casas conmovidos y en crisis.

Pero en la clase también acaece otro encuentro: el diálogo con los otros. La etimología de diálogo reclama la presencia de un "tư". Un tú que me saca, me conmina, me hostiga - diría Lévinas -. A través de la presencia del otro no sólo me siento acompańado en el universo por alguien a quien reconozco 
"hueso de mis huesos", según la expresión hebraica, sino que el otro también me incomoda, desinstala y en esa medida me perfecciona. En las lecciones, soportar al otro es aprender a convivir con la diferencia en la mismidad: no hay otro tan idéntico a mí aunque tan radicalmente distinto a mí. Por eso el diálogo con el maestro o los co-hermanos será siempre un camino de conversión política, la academia forja el espíritu para la diferencia. Aprender a hablar en clase precisa aprender a pensar en los demás. Lo mismo que precisa el arte de discutir o persuadir. Incluso estas experiencias precisan de aprender a intuir, como en el ajedrez, el argumento del contrincante. En la ética cristiana, aprender a dialogar implica la búsqueda amorosa de la verdad. Como diría el gran teólogo Von Balthasar: titulando uno de sus textos: "La verdad es sinfónica". Las lecciones de clase son un taller de vida política.

Pero en este nivel de diálogo, hay uno de belleza sin par: aprender a leer que implica saber dialogar con los muertos. Esta expresión tiene un correlato más grotesco en la respuesta que el oráculo de Apolo le da a Zenon cuando le pregunta qué hacer para alcanzar la sabiduría: si quieres ser sabio, "copula con los muertos". Otras versiones permitirán decir: duerme con los muertos, acuéstate con los muertos o quizá dialoga con los muertos. La tradición posterior comprendió esta expresión como: si quieres ser sabio, lee a los clásicos.

La sabiduría se esconde también en el noble ejercicio de leer, justo porque leer es más que unir letras: leer es saber dialogar con los clásicos, con los antiguos, con la tradición. Por eso no existe formación sin lectura, porque no existe formación del espíritu sin tradición. Saber leer, además, requiere de una cierta paciencia. La expresividad del autor queda supeditada a unos signos gráficos que a veces no logran transmitir. Pero cuando detonan su poder en el corazón humano, su poder es devastador. ¿Quién puede robar la conmoción que genera la lectura de un texto? Jesús lo supo: el ámbito que genera la lectura en la vida interior es semejante a aquella habitación donde los ladrones no roban ni la polilla corroe. Es esa reserva interior en la que queda fecundada la intuición de un nuevo amigo porque, además, cada libro es eso: un nuevo amigo.

Leer bien, leer espiritualmente, es tener en frente muchos amigos. Hay amigos con los que se discute todo el día, hay amigos que apenas se les escucha y luego se les cierra; hay amigos con los que discrepamos y hay 
amigos que incluso llevamos a la cama. ¡Cada libro es un amigo! O como decía el maestro de una vieja película española, la lengua de las mariposas: un libro es donde uno guarda sus sueños para que no se mueran de frío. Mientras un espíritu perezoso ve en la lectura puesta por su maestro una piedra que debe cargar como Sísifo y subir con ella a la montańa, los espíritus hondos agradecen a su Maestro que le presente a sus mejores amigos. Después de un coloquio con ellos, nunca se podrá ser igual.

\section{Saber escribir}

Un último ejercicio espiritual es también el escribir. Se pone de moda en los actuales modelos pedagógicos incentivar a los discípulos y docentes para que escriban. Hoy incluso se pide que los alumnos escriban ensayos en todos sus cursos y a los profesores se les motiva para que publiquen, no vaya a ser que se les aplique un sarcástico chiste de la universidad de Harvard seńalando a Jesús: "fue un buen maestro, pero no publicó”. Pero, ¿por qué escribir?

Esta misma pregunta se la hace la filósofa española María Zambrano (1934):

Escribir es defender la soledad en que se está; es una acción que sólo brota desde un aislamiento efectivo, pero desde un aislamiento comunicable, en que precisamente por la lejanía de toda cosa concreta se hace posible un descubrimiento de relaciones entre ellas. Pero es una soledad que necesita ser defendida, que es lo mismo que necesitar de una justificación. El escritor defiende su soledad, mostrando lo que en ella y únicamente en ella se encuentra (p. 318).

Se escribe para salir de la soledad y abrirse a la comunión. Si trascender es salir de sí, escribir es trascender y como trascender es difícil, por eso escribir también lo es. Es angustiante estar de frente a la hoja en blanco porque ella exige salir de sí. La hoja llama y reclama. Convoca y provoca. La hoja en blanco pregunta y cuando de repente se toma la decisión de poner unas letras, pronto ella misma se burla de las incoherencias. Escribir exige conocerse a sí mismo. La escritura refleja que lo que se tiene por claro no lo es tanto. Por eso la escritura es ejercicio espiritual. Porque pone en marcha el diálogo consigo mismo y con los demás, una noble tarea que la hermenéutica reconoce como fusión de horizontes. 
La escritura es también comunión, sobre todo, con el ausente. La enseñanza esotérica - para el grupo de clase - se vuelve exotérica - para los que no están en el aula - con la escritura. En parte, esto fue lo que movió a Platón a escribir sus diálogos: el gozo de saber que los ausentes podrían participar de las clases de la academia. Y fue la misma motivación de los evangelistas: narrar lo que "vieron y oyeron" para que a los demás alcanzara la vida que a ellos había llegado.

Por esta misma razón los novios se escriben cartas y los judíos ponen sus quejas en el muro de las lamentaciones y así todos los que escriben están clamando por ser escuchados, bien sea por los otros, por Dios o en última instancia, por ellos mismos. Marco Aurelio fue uno que escribió para sí mismo. Incluso solo por esto, bastaría asumir el riesgo de escribir.

\section{EL DESAFÍO}

Como se puede ver, estos tres ejercicios perviven en el normal desenvolvimiento de las lecciones en los claustros académicos hodiernos. Con un leve descuido, estas prácticas pueden ser experimentadas como lejanas de la vida, apéndices a ella, mientras la mente sueña con un futuro promisorio en el que como profesionales en determinadas áreas del saber, serán los modernos redentores del universo a modo de los grandes héroes de las caricaturas. Pero también pueden ser vividas como una auténtica y vívida experiencia espiritual.

He aquí el desafío que quiere proponer estas letras a maestros y discípulos, a los ejercitantes de la filosofía y la teología y, en ellos, a todas las personas que se reconocen en el ámbito de la formación: la vida no es el futuro. La vida es hoy y mientras se transite por los senderos de la vida escolar, abracen ese momento con hondura espiritual. La conversión no espera: "carpe diem", vive el cada día. Estudiar de este modo transforma la vida: las aulas toman calle, el tiempo se hace cotidiano y así los conceptos entran en los ámbitos públicos y privados, se tornan nuevas relaciones y hacen de la interioridad una casa habitable, un lugar donde cada individuo quiere permanecer morando. 
El arte de estudiar como preludio del saber vivir. Una interpretación

de las prácticas escolares como ejercicios espirituales

\section{LISTA DE REFERENCIAS}

Foucault, M. (2005). La hermenéutica del sujeto. Madrid: Ediciones AKAL S.A.

Hadot, P. (1995). Qu'est-ce que la philosophie antique?. Paris, Gallimard, 1995. Paris: Gallimard.

. (2001). La philosophie comme manière de vivre. Entretiens avec Jean Carlier et Arnold Davidson. París: Albin Michel.

. (2002). Exercices spirituels et philosophie antique. Paris: Albin Michel.

Pérez Cortés, S. (2004). Palabras de filósofos. Oralidad, escritura y memoria en la filosofía antigua. México: Siglo XXI Editores.

Platón. (2014). Apología 29d-30b. Madrid: Alianza editorial.

Platón. (s.f.). Carta VII, 330c-331a.

Sampson, A. (1997). Lectura y cuidado de sí. Revista Universidad del Valle, 16, 4-16.

Spanneut, M. (1957). Le Stoïcisme des Pères de l'Église, de Clément de Rome à Clément d'Alexandrie. Paris: Le Seueil.

Steiner, G. (2004). Lecciones de los maestros. México: Siruela.

Zambrano, M. (1934). ¿Por qué se escribe? Revista de Occidente, XLIV, 318. 